\title{
Mapeamento e avaliação ecológica de Áreas de Preservação Permanente do rio Catu, Alagoinhas, Bahia, Brasil
}

\author{
Grice Anne dos Santos Vaz ${ }^{1,2^{*}}$ \& Mara Rojane Barros de Matos ${ }^{2, a}$ \\ ${ }^{1}$ Universidade Tecnológica Federal do Paraná, Curitiba, Paraná, Brasil. \\ ${ }^{2}$ Universidade do Estado da Bahia-Campus II, Alagoinhas, Bahia, Brasil.
}

\begin{abstract}
Resumo - A microbacia do rio Catu é parte da Bacia Hidrográfica do Recôncavo Norte e vem sendo degradada pela ação antrópica há décadas. Para conhecer melhor a situação do rio Catu, este trabalho avaliou e mapeou a integridade ecológica de fragmentos de vegetação na Área de Preservação Permanente ao longo do seu curso. Nós usamos o índice de Vulnerabilidade Ecológica Relativa, a conectividade da paisagem, o Índice de Funcionalidade Fluvial e uma chave para tomada de decisões na recuperação de áreas degradadas. Nossos resultados mostram que os fragmentos florestais ao longo do rio Catu estão bastante isolados e mais de $50 \%$ encontram-se altamente vulneráveis à perda de biodiversidade. O menor nível de funcionalidade fluvial foi encontrado na área urbana e o maior em um remanescente florestal na cidade de Alagoinhas. Além da execução das principais ações para recuperação das áreas diagnosticadas, é necessária maior fiscalização do cumprimento das leis ambientais e uma revisão do planejamento urbano.

Palavras-chave adicionais: Área de Proteção Ambiental, fragmentação, vegetação ciliar, vulnerabilidade ecológica.
\end{abstract}

\begin{abstract}
Mapping and ecological assessment of Permanent Preservation Areas along the Catu river in Alagoinhas, Bahia State, Brazil) The Catu river micro-basin is part of the North Reconcavo Hydrographic Basin that has been experiencing degradation due to anthropogenic disturbances during recent decades. To better understand the status of the Catu river, the present study evaluated and mapped the ecological integrity of the vegetation fragments in the Permanent Preservation Area along its banks. We used the Relative Ecological Vulnerability index, the landscape connectivity, the Fluvial Functionality Index and a decision-making key for recovering degraded areas. Our results show that forest fragments along the Catu river are very isolated and more than $50 \%$ are highly vulnerable to biodiversity losses. The lowest level of fluvial functionality was found in urban areas and the highest in a remnant forest area within the city of Alagoinhas. In addition to the implementation of key actions for the recovery of the diagnosed areas, higher enforcement of environmental laws will be required, as well as urban planning reviews.
\end{abstract}

Additional keywords: ecological vulnerability, Environmental Protection Area, fragmentation, riparian vegetation.

As Áreas de Preservação Permanente (APP) são definidas pela Lei $\mathrm{n}^{\mathrm{o}} 12.651$ de 25 de maio de 2012, como áreas protegidas, cobertas ou não por vegetação nativa, com a função ambiental de preservar os recursos hídricos, a paisagem, a estabilidade geológica e a biodiversidade, facilitar o fluxo gênico de fauna e flora, proteger o solo e assegurar o bem-estar das populações humanas. Dentre outras áreas em zonas rurais e urbanas, essa Lei considera como APP as faixas marginais de qualquer curso d'água natural perene e intermitente, as áreas no entorno dos lagos e lagoas naturais, no entorno dos reservatórios d'água artificiais, decorrentes de barramento ou represamento de cursos d'água naturais, no entorno das nascentes e dos olhos d'água perenes. A faixa mínima a ser preservada é delimitada de acordo com o tipo e a largura do curso d'água.

A vegetação ciliar localiza-se numa região de interface entre ecossistemas terrestre e aquático conhecida como zona ripária. Levando em conta a integridade da microbacia hidrográfica, as zonas ripárias são as áreas mais dinâmicas da paisagem, tanto

\footnotetext{
*Autora para correspondência: griceannevaz@hotmail.com;

amararmatos@yahoo.com.br

Editor responsável: Alessandro Rapini

Submetido: 21 jan. 2014; aceito: 5 maio 2014

Publicação eletrônica: 20 dez. 2014; versão final: 20 jan. 2015
}

em termos hidrológicos, como ecológicos e geomorfológicos (Lima \& Zakia 2000). Preservada ou restaurada, ela desempenha várias funções importantes na manutenção da qualidade da água, estabilidade térmica e dos solos de áreas marginais, regularização dos regimes hídricos através de sua influência no lençol freático, além de atuar no sustento da fauna aquática e silvestre ribeirinha (Sgrott 2003). A influência dessa vegetação é ainda maior na parte montante da bacia, onde os cursos da água são caracterizados por pequena largura, velocidade, vazão, profundidade, dentre outras variáveis (Vannote et al. 1980).

Apesar da reconhecida importância da vegetação nas APP, essas áreas também não escaparam da destruição, principalmente pelo fato de que muitas cidades foram formadas às margens dos rios, eliminando a vegetação ciliar, e muitas sofrem hoje os efeitos negativos, com inundações constantes. Os paradigmas de desenvolvimento no Brasil estimularam a exploração descontrolada da flora, fauna, recursos hídricos e minerais, bem como a posse indevida de faixas de terra (Ferreira \& Dias 2004). Com isso, além de se tornarem escassos, os recursos naturais estão sendo submetidos a substituição de áreas naturais extensas e contínuas da paisagem por fragmentos circundados por uma matriz urbana ou agrícola. Essa crescente taxa de modificações antrópicas na paisagem 
resulta na fragmentação e perda de hábitat (ForeroMedina \& Vieira 2007), alterando a composição e a diversidade das comunidades (Pereira et al. 2010), que são geralmente arroladas como os principais fatores ameaçando a biodiversidade (Saunders et al. 1991). Neste contexto, pode ser citado o rio Catu, parte da Bacia Hidrográfica do Recôncavo Norte, que há décadas vem sofrendo diversos tipos de degradação pela ação antrópica.

Ecologia da paisagem é uma abordagem essencial para se diagnosticar transformações decorrentes do uso e ocupação do solo, bem como avaliar a extensão da vegetação nas margens dos cursos d'água. Outro instrumento amplamente utilizado é o Protocolo de Avaliação Rápida, que permite o diagnóstico da alteração ambiental através de uma metodologia fácil, simples e de rápida aplicação que, por meio de uma inspeção visual da área, capta as características do hábitat para avaliação da qualidade ambiental.

No intuito de contribuir para o conhecimento da situação do rio Catu, uma microbacia ainda pouco estudada, a presente pesquisa teve como objetivos principais avaliar e mapear a integridade ecológica dos fragmentos de vegetação nativa remanescente na Área de Preservação Permanente do rio Catu, estado da Bahia, Brasil.

\section{MATERIAL E MÉtodos}

Área de estudo. O rio Catu é uma microbacia integrante da Bacia Hidrográfica do Recôncavo Norte. Situa-se entre as coordenadas $12^{\circ} 00^{\prime}-12^{\circ} 25^{\prime} \mathrm{S}$ e $38^{\circ} 15^{\prime}-$ $38^{\circ} 30^{\prime} \mathrm{W}$, nasce no município de Aramari, passa pelas cidades de Alagoinhas e Catu, e deságua no rio Pojuca (Figura 1). Trata-se de um rio pouco estudado que carece de pesquisas do ponto de vista dos processos ecossistêmicos, hidrológicos e da paisagem.

Mapeamento. O mapeamento digital foi feito através da classificação da imagem e vetorização dos fragmentos vegetacionais da área urbana e do rio. Foram utilizadas imagens de satélite do Google Earth Pro (ano 2008) e o ArcGIS 9.3, ESRI, para o tratamento da imagem utilizando o sistema de projeção Universal Transversa de Mercartor (UTM) e Datum WGS. Nesse mapeamento, foi utilizada também a base vetorial cartográfica de hidrografia e municipal na escala 1:50.000 do IBGE. A Área de Preservação Permanente (APP) foi espacializadas com base na atual Lei $12.651 / 2012$, que delimita o mínimo de $30 \mathrm{~m}$ para os cursos d'água de até $10 \mathrm{~m}$ de largura e raio mínimo de $50 \mathrm{~m}$ para as nascentes e lagos. Para avaliação da conectividade estrutural, também foi mapeada a Área de Proteção Ambiental (APA), onde localizava-se a antiga nascente do curso principal do rio Catu, e os fragmentos florestais com distâncias de até $350 \mathrm{~m}$ da APP, conforme índices utilizados por Pires et al. (2004).
Avaliação da integridade ecológica da paisagem. A integridade ecológica da paisagem foi analisada através dos índices de Vulnerabilidade Ecológica Relativa (VER) e conectividade da paisagem (grau de isolamento de fragmentos de áreas naturais), calculada segundo Pires et al. (2004). A VER foi calculada com base nos condicionantes de tamanho indicados pela relação interior/borda, delimitando para o cálculo da borda uma faixa de $30 \mathrm{~m}$ da borda para o interior do fragmento, considerando o restante da área como interior. Para analisar a conectividade da paisagem, foram utilizadas distâncias (d) expandidas a partir da borda do polígono, previamente determinadas de 30 , 50,100,150,200, 300 e 350 m, conforme distâncias utilizadas por Ranta et al. (1998) e Pires et al. (2004). Um fragmento foi considerado isolado de outros a uma distância d quando não havia sobreposição de sua área de borda com a área de outro polígono, conforme a distância previamente determinada e expandida através do buffer no ArcGIS. Quando houve sobreposição da borda expandida sobre um ou mais fragmentos vizinhos, eles foram considerados conectados à distância d determinada. Considerando espécies de menor plasticidade, Pires et al. (2004) considerou a distância de borda expandida de $350 \mathrm{~m}$ como limite de locomoção para a maioria das espécies em áreas abertas na paisagem.

Diagnóstico da conservação e degradação. Em um trecho de $21 \mathrm{~km}$ ao longo do rio Catu, foram determinados sete pontos para a avaliação (Tabela 1; Figura 1), utilizando uma amostragem sistemática, com intervalo aproximado de $3 \mathrm{~km}$. Foram diagnosticados, também, o local da antiga nascente e uma lagoa próxima ao rio. Com exceção do "Ponto 1", onde não há mais afloramento do lençol freático, e do "Ponto 9", que é um ecossistema lêntico, o diagnóstico foi realizado por meio da aplicação do formulário IFF (Índice de Funcionalidade Fluvial), um método com abordagem holística proposto por Siligardi et al. (2007).

O IFF investiga o ecossistema do rio como um todo e identifica características físico-morfológicas para avaliação do estado geral do ambiente do rio e sua funcionalidade a partir de uma inspeção visual. Ele é composto por 14 questões com quatro respostas devidamente ponderadas associadas à pontuação. $\mathrm{O}$ valor de IFF é calculado para cada curso e lado através da soma da pontuação do leito e das margens separadamente, podendo obter o valor mínimo de 14 e máximo de 300 . Esse valor pode ser classificado em cinco níveis de funcionalidade e cores para o mapeamento (nesse trabalho, foi adotado apenas $o$ nível de funcionalidade), sendo o nível "I" a melhor situação, o "V" a pior, e os níveis intermediários às transições de um nível a outro. Para caracterização de áreas degradadas, foi utilizada a chave de tomada de decisão na recuperação de áreas degradadas proposta por Ivanauskas \& Barbosa (2006), a qual contempla os principais aspectos e situações de degradação 


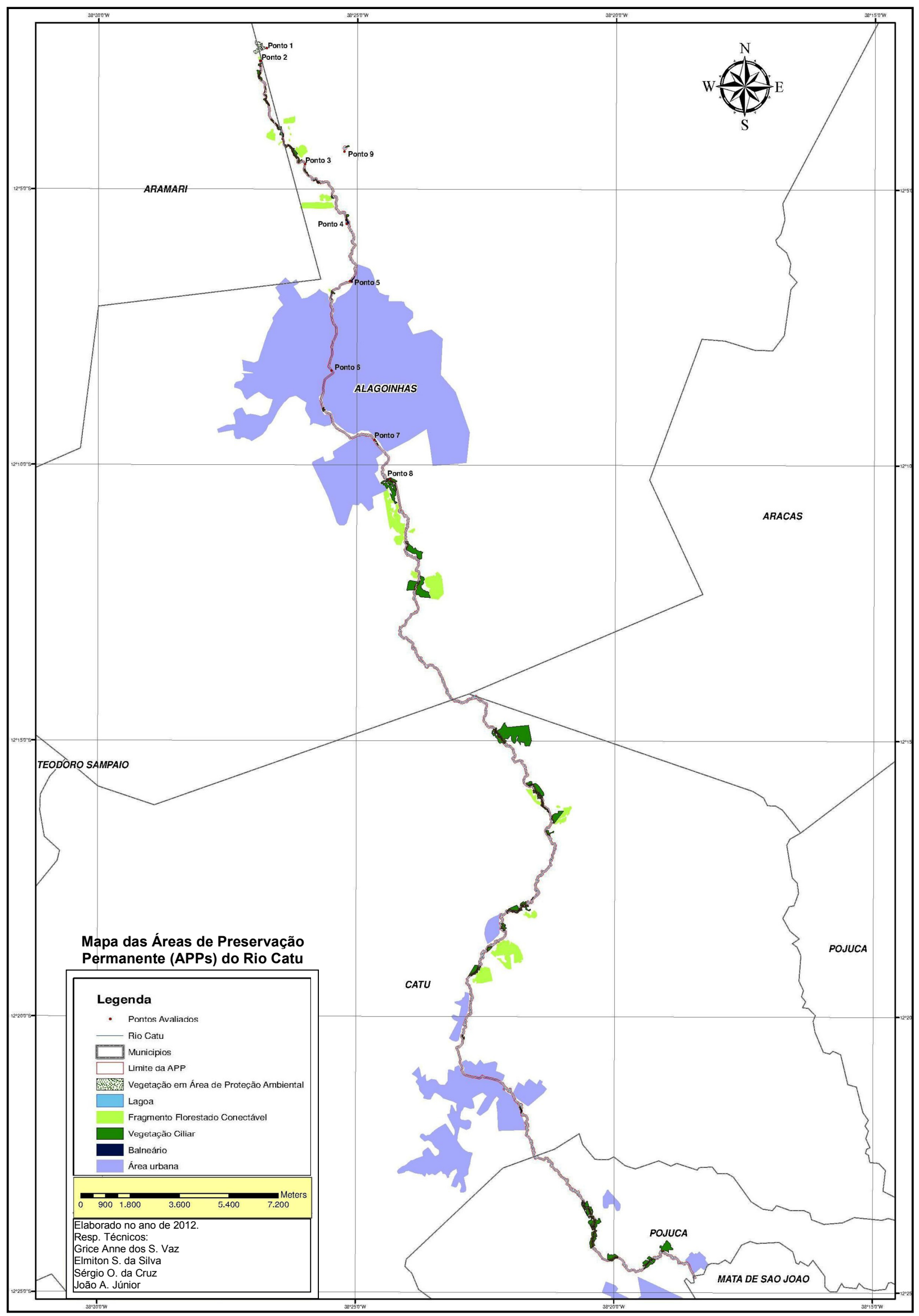

Figura 1. Mapa das Áreas de Preservação Permanente do Rio Catu, estado da Bahia, Brasil, mostrando os pontos avaliados quanto à integridade ecológica. 
Tabela 1. Pontos diagnosticados ao longo do Área de Preservação Permanente do Rio Catu, estado da Bahia, Brasil, 2012.

\begin{tabular}{lll}
\hline Pontos & Localidade & Coordenadas \\
\hline Ponto 1 & Antiga nascente do curso principal & $12^{\circ} 02^{\prime} 28^{\prime \prime} \mathrm{S}$ \\
& do rio Catu & $38^{\circ} 26^{\prime} 46^{\prime \prime} \mathrm{W}$ \\
Ponto 2 & Atual nascente do curso principal & $12^{\circ} 02^{\prime} 43^{\prime \prime} \mathrm{S}$ \\
& do rio Catu & $38^{\circ} 26^{\prime} 53^{\prime \prime} \mathrm{W}$ \\
Ponto 3 & Fazenda Rancho do Budog & $12^{\circ} 04^{\prime} 39^{\prime \prime} \mathrm{S}$ \\
& & $38^{\circ} 26^{\prime} 01^{\prime \prime} \mathrm{W}$ \\
Ponto 4 & Balneário Parque das Águas & $12^{\circ} 05^{\prime} 39^{\prime \prime} \mathrm{S}$ \\
& & $38^{\circ} 25^{\prime} 10^{\prime \prime} \mathrm{W}$ \\
Ponto 5 & Balneário Mr. Johannrs & $12^{\circ} 06^{\prime} 40^{\prime \prime} \mathrm{S}$ \\
& & $38^{\circ} 25^{\prime} 08^{\prime \prime} \mathrm{W}$ \\
Ponto 6 & Praça Padre Alfredo & $12^{\circ} 08^{\prime} 18^{\prime \prime} \mathrm{S}$ \\
& & $38^{\circ} 25^{\prime} 31^{\prime \prime} \mathrm{W}$ \\
Ponto 7 & Alagoinhas (Viaduto BR-101) & $12^{\circ} 10^{\prime} 19^{\prime \prime} \mathrm{S}$ \\
& & $38^{\circ} 24^{\prime} 41^{\prime \prime} \mathrm{W}$ \\
Ponto 8 & Próximo à UNEB-Campus II & $12^{\circ} 10^{\prime} 19^{\prime \prime} \mathrm{S}$ \\
& & $38^{\circ} 24^{\prime} 25^{\prime \prime} \mathrm{W}$ \\
Ponto 9 & Lagoa do Buri & $12^{\circ} 04^{\prime} 17^{\prime \prime} \mathrm{S}$ \\
& & $38^{\circ} 25^{\prime} 15^{\prime \prime} \mathrm{W}$ \\
\hline
\end{tabular}

ambiental e as principais ações recomendadas para cada caso. Essa chave apresenta possibilidades mútuas e exclusivas que conduzem a uma série de ações possíveis ou a um novo item com uma nova bifurcação. O grau de degradação é avaliado de acordo com a fisionomia, composição e estrutura florestal, tendo como pontos positivos a riqueza, número de estratos (incluindo regenerantes), presença de epífitas, e pontos negativos a presença de lianas em desequilíbrio (borda e interior) e gramíneas invasoras (borda e interior). Essa chave contempla diversas situações, características da área em questão, principais aspectos de degradação ambiental e as ações recomendadas para cada caso.

\section{RESULTADOS}

O rio Catu percorre $74 \mathrm{~km}$, desde a nascente no município de Aramari até o encontro com o rio Pojuca. No mosaico de sua paisagem, são encontradas pequenas manchas florestadas isoladas, mostrando a extrema fragmentação da vegetação (Figura 1).

Análise da integridade ecológica. No total, foram mapeadas 84 manchas (Tabela 2) de APP, incluindo os fragmentos localizados no local da antiga nascente do curso principal do rio (atualmente, uma APA). O menor fragmento tem 0,06 ha e o maior 56,06 ha. $\mathrm{O}$ somatório das áreas de todos os fragmentos corresponde a 243,85 ha, totalizando uma área média de aproximadamente 2,90 ha por fragmento, com desvio padrão de 6,679 e coeficiente de variância de $230 \%$.
Tabela 2. Número de fragmentos florestais em Área de Preservação Permanente ou Área de Proteção Ambiental (área da antiga nascente) ao longo do rio Catu por classes de tamanho.

\begin{tabular}{cc}
\hline Classes de tamanho (ha) & Número de fragmentos (\%) \\
\hline$<5$ & $74(88,1 \%)$ \\
5 a 50 & $9(10,71 \%)$ \\
$>50$ & $1(1,19 \%)$ \\
\hline Total & $\mathbf{8 4}(\mathbf{1 0 0 \% )}$ \\
\hline
\end{tabular}

O menor valor de VER foi 0,01 e o maior, 3,08, que corresponde à mancha com maior área (56,06 ha), sendo o único fragmento que apresentou média VER $(>2,5$ e $<5)$. Mais da metade $(54,76 \%)$ dos fragmentos na menor classe de tamanho $(<5)$ teve o cálculo da VER impossibilitado tanto pelo tamanho quanto pela forma (Tabela 3 ).

$\mathrm{Na}$ avaliação da conectividade, mesmo considerando a borda expandida de $350 \mathrm{~m}, 52$ fragmentos permanecem isolados na paisagem, representando $61,90 \%$ da área total dos remanescentes. Apenas cinco $(4,76 \%)$ conexões foram realizadas com a menor distância considerada entre os fragmentos (30 $\mathrm{m})$. Dos fragmentos conectáveis, as distâncias mais frequentes foram de 150 (6 fragmentos) e $200 \mathrm{~m}$ (6 fragmentos cada) (Tabela 4).

Análise da conservação e degradação. A abordagem da análise dos resultados da aplicação do formulário IFF foi realizada pelo agrupamento de níveis mais próximos.

Nível "Péssimo" a "Médio" (V a III). Neste grupo, encontram-se os Pontos 2, 3, 4 e 6, em condições consideradas mais graves, pela pontuação avaliada com o IFF (Quadro 1). O Ponto 2 é o local da atual nascente do curso principal do rio Catu. Está localizado numa fazenda. Na margem esquerda, encontra-se um campo de pastagem, e na direita, uma pequena faixa de vegetação perifluvial que apresenta espécies arbóreas e arbustivas com altura média entre 5 e $12 \mathrm{~m}$, solo arenoso, fina camada de serrapilheira pouco decomposta e descontínua.

Tabela 3. Valores do índice de Vulnerabilidade Ecológica Relativa (VER) de fragmentos florestais ao longo do rio Catu por classe de tamanho (ha).

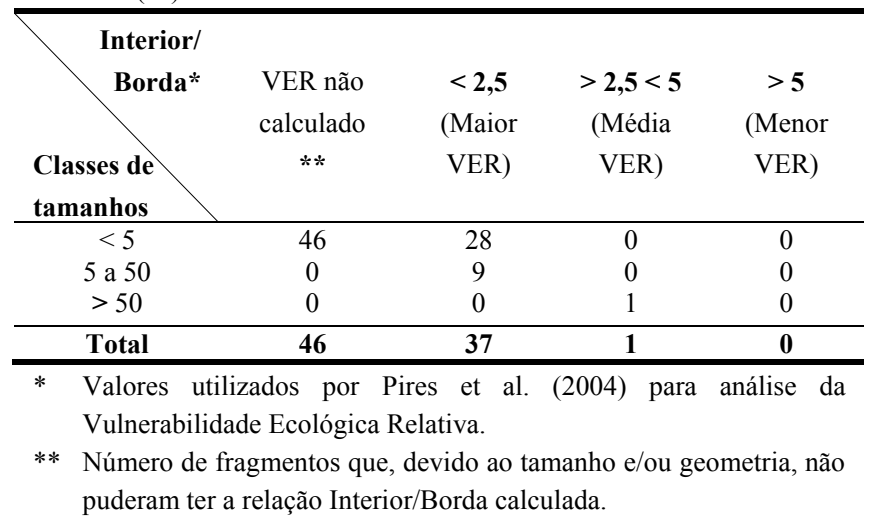


Tabela 4. Número de fragmentos florestais na Área de Preservação Permanente ao longo do rio Catu que apresentam conectividade a distâncias (d) pré-determinadas a partir da análise da conectividade estrutural dos fragmentos florestais. - (ausência de fragmentos)

\begin{tabular}{|c|c|c|c|c|c|c|c|c|}
\hline Classes & $30 \mathrm{~m}$ & $50 \mathrm{~m}$ & $100 \mathrm{~m}$ & $150 \mathrm{~m}$ & $200 \mathrm{~m}$ & $250 \mathrm{~m}$ & $300 \mathrm{~m}$ & $350 \mathrm{~m}$ \\
\hline$<5$ & 5 & 3 & 1 & 5 & 6 & 2 & 3 & 1 \\
\hline 5 a 50 & - & 2 & 2 & 1 & - & - & - & 1 \\
\hline$>50$ & - & - & - & - & - & - & - & - \\
\hline Total & 5 & 5 & 3 & 6 & 6 & 2 & 3 & 2 \\
\hline
\end{tabular}

Com pontuação mediana, o trecho do rio Catu no Ponto 3 (Quadro 1) atravessa uma fazenda onde há uma ponte para $\mathrm{o}$ trânsito de caminhões, não sendo verificadas mudanças drásticas no curso do rio nem no seu substrato. Nesse mesmo trecho, uma mata bem preservada sobre morros é encontrada a montante do rio.

No Ponto 4, há um represamento do rio Catu para fins recreativos (balneário) modificando boa parte do seu cenário natural. Nessa área recreativa, o terreno é circundado por campo, pastagem com árvores isoladas e margens com poucos estratos gramados.

Com nível de funcionalidade fluvial considerado "péssimo" (Quadro 1), o trecho do ponto 6 localiza-se na área urbana onde o rio sofre canalização e total ausência de vegetação perifluvial. Recebendo lançamento de esgotos e resíduos sólidos, sua água é opaca e apresenta forte odor.

Nível "Muito bom" a "Excelente" (II-III a 0). Abrange os Pontos 5, 7 e 8, circundados por campo, pastagem e floresta. O Ponto 5 (assim como o Ponto 4) também consiste de um represamento do rio Catu para fins recreativos, em menor grau. As margens planas reduzem o escoamento e favorecem a infiltração da água pelo solo.

Os Pontos 7 e 8 localizam-se na saída da área urbana (Figura 1). No Ponto 7, o rio Catu passa por baixo de um viaduto e o nível de funcionalidade fluvial foi médio (Quadro 1). Na margem direita, há formações arbóreas ripária com predominância de pastagem e, na margem esquerda, há uma pequena faixa de vegetação ciliar entre 25 e $30 \mathrm{~m}$ com fisionomia arbórea

Dentre os pontos avaliados, o Ponto 8 foi o único classificado com nível de funcionalidade excelente (Quadro 1). Uma cerca divide o fragmento florestal de uma área de pastagem, o que não impede a circulação de gado nesse e em outros trechos. A área circundante é formada por floresta com clareiras, o trecho sofre inundações com chuvas frequentes e o leito se apresenta diversificado e estável com presença de aguapés a jusante do rio. É caracterizada como uma Floresta Ombrófila Densa, onde estão presentes espécies como Miconia sp., Rapanea sp., Myrcia sp., Inga sp., Symphonia globulifera L. f. e Tapirira guianensis Aubl.
Antiga nascente (Ponto 1) e Lagoa do Buri (Ponto 9). A antiga nascente (Ponto 1), localizada na APA da antiga nascente do rio Catu, que possui $7.850 \mathrm{~m}^{2}$, encontra-se seca, sem afloramento do lençol freático. Trata-se de uma área em processo de reflorestamento sob a responsabilidade de uma empresa de silvicultura no município de Alagoinhas, através do projeto Catuzinho. A cobertura vegetal ainda não forma um dossel fechado, a fisionomia é composta por espécies arbóreas e arbustivas predominantemente entre 2 e 10 $\mathrm{m}$ de altura; o solo é arenoso e a serrapilheira forma uma fina camada pouco decomposta. O trânsito de animais (gado e cavalo) nessa área é frequente, o que pode comprometer o sucesso do reflorestamento.

No Ponto 9, há uma lagoa próxima ao rio Catu, a Lagoa do Buri, com perceptível assoreamento. Inserida numa matriz agropecuária, ela apresenta suas margens instáveis, poucas árvores, com faixa de APP em desacordo com o exigido na atual legislação, que determina raio mínimo de $50 \mathrm{~m}$.

\section{DISCUSSÃo}

Os resultados mostram a extrema fragmentação da cobertura vegetal na APP do Rio Catu e o tamanho da maioria deles é insuficiente para garantir a perpetuação de algumas espécies (Tabela 3). A fragmentação da vegetação leva à perda de hábitat, redução do tamanho das manchas de vegetação nativa e aumento do isolamento entre elas (Andrén 1994). Com a fragmentação de uma vegetação contínua em uma matriz de hábitat desfavorável, o número de espécies em cada fragmento acompanha a diminuição na área, reduzindo até ajustar-se ao novo tamanho de cada fragmento (Forero-Medina \& Vieira 2007). Para Pires et al. (2004), os efeitos de uma fragmentação estão relacionados ao tamanho, número de remanescentes, e às suas implicações sobre o efeito de borda e isolamento entre fragmentos. Isso pode acarretar limitações na quantidade e na qualidade de hábitats, no movimento das espécies e no tamanho de suas populações. Fragmentos de boa qualidade tenderão a um excedente demográfico, enquanto aqueles de baixa qualidade tenderão a um déficit demográfico (Delibes et al. 2001). 
Quadro 1: Nível do Índice de Funcionalidade Fluvial (IFF) dos pontos e ações recomendadas nos trechos da Área de Preservação Permanente ao longo do rio Catu, estado da Bahia, Brasil.

\begin{tabular}{|c|c|c|c|c|c|}
\hline \multirow{2}{*}{ Pontos } & \multicolumn{4}{|c|}{ IFF } & Chave de tomada de decisões \\
\hline & \multicolumn{2}{|c|}{ Margem esquerda } & \multicolumn{2}{|c|}{ Margem direita } & Ações recomendadas \\
\hline 1 & \multicolumn{4}{|c|}{$\begin{array}{c}\text { Não se aplica. } \\
\text { (Área de reflorestamento) }\end{array}$} & $\begin{array}{l}\text { Área em processo de recuperação pelo } \\
\text { projeto Catuzinho. }\end{array}$ \\
\hline 2 & \multicolumn{2}{|c|}{ (IV) Ruim } & (III- IV) & $\begin{array}{l}\text { Médio a } \\
\text { ruim }\end{array}$ & $\begin{array}{l}\text { Implantação de zona tampão; } \\
\text { enriquecimento florístico com diversidade } \\
\text { genética; manejo de espécie-problema. }\end{array}$ \\
\hline 3 & \multicolumn{2}{|c|}{ (III) Médio } & \multicolumn{2}{|c|}{ (III) Médio } & $\begin{array}{l}\text { Indução e condução da regeneração; } \\
\text { adensamento e enriquecimento florístico } \\
\text { com diversidade genética; nucleação } \\
\text { (ilhas de diversidade); implantação de } \\
\text { zona tampão. }\end{array}$ \\
\hline 4 & \multicolumn{2}{|c|}{ (III) Médio } & \multicolumn{2}{|c|}{ (III) Médio } & $\begin{array}{l}\text { Conservação e descompactação do solo; } \\
\text { plantio em área total (mudas ou } \\
\text { semeadura); nucleação (ilhas de } \\
\text { diversidade); implantação de zona } \\
\text { tampão. }\end{array}$ \\
\hline 5 & (II-III) & Razoável & (II-III) & Razoável & $\begin{array}{l}\text { Implantação de zona tampão; } \\
\text { enriquecimento florístico com diversidade } \\
\text { genética; manejo de espécie-problema. }\end{array}$ \\
\hline 6 & \multicolumn{2}{|c|}{ (V) Péssimo } & \multicolumn{2}{|c|}{ (V) Péssimo } & Não se aplica. Área urbana. \\
\hline 7 & (II-III) & Razoável & \multicolumn{2}{|c|}{ (III) Médio } & $\begin{array}{l}\text { Implantação de zona tampão; } \\
\text { enriquecimento florístico com diversidade } \\
\text { genética; manejo de espécie-problema. }\end{array}$ \\
\hline 8 & \multicolumn{2}{|c|}{ (0) Excelente } & \multicolumn{2}{|c|}{ (0) Excelente } & $\begin{array}{l}\text { Implantação de zona tampão; } \\
\text { enriquecimento florístico com diversidade } \\
\text { genética; manejo de espécie-problema. }\end{array}$ \\
\hline 9 & \multicolumn{4}{|c|}{$\begin{array}{l}\text { Não se aplica. } \\
\text { (Lagoa) }\end{array}$} & $\begin{array}{l}\text { Implantação de zona tampão; } \\
\text { enriquecimento florístico com diversidade } \\
\text { genética; manejo de espécie-problema. }\end{array}$ \\
\hline
\end{tabular}

O efeito de borda e a vulnerabilidade dos fragmentos estão diretamente relacionados ao tamanho e à forma desses fragmentos (Azevedo et al. 2003). Assim, a geometria das manchas de hábitat pode afetar a dinâmica populacional, influenciando a biodiversidade, o tamanho e o formato da área de ação, o comportamento de dispersão animal e a abundância das espécies (Odum \& Barret 2007). Manchas circulares maximizam o hábitat das espécies de interior, enquanto manchas longas, lineares e estreitas, maximizam o hábitat das espécies de borda. É provável que o hábitat de interior seja eliminado por completo em fragmentos estreitos e alongados, limitando ou impedindo de forma severa as espécies de animais e plantas de interior.

Comparando os valores de VER dos fragmentos florestais na APP do rio Catu com aqueles adotados por Pires et al. (2004), percebe-se que nenhum apresenta VER baixa (relação Interior/Borda > 5). Como VER é inversamente proporcional a vulnerabilidade ambiental do fragmento florestado, este resultado indica que a integridade ecológica desses fragmentos encontra-se bastante comprometida. Mais de 90\% dos fragmentos estudados encontram-se altamente vulneráveis à perda de biodiversidade (fragmentos de tamanho e/ou forma inviáveis e $\mathrm{VER}<2,5$ ). 
Nesta pesquisa, avaliou-se apenas a conectividade estrutural através de índices espaciais que descrevem os atributos das manchas e proporcionam informações relevantes à medição da fragmentação. Entretanto, segundo Forero-Medina \& Vieira (2007), existe uma diferença entre conectividade estrutural, que leva em consideração somente aspectos físicos da paisagem, e a conectividade funcional, que depende da capacidade de dispersão dos organismos. Esta última explica e dá sentido à primeira. Portanto, é necessário estudar aspectos comportamentais de cada espécie e fazer uma relação entre essas características e a conectividade da paisagem, definida por Taylor et al. (1993) como o grau no qual a paisagem facilita ou impede o movimento dos organismos entre manchas.

De modo geral, o isolamento dos fragmentos florestais examinados da APP compromete sua integridade ecológica e funcionalidade. Pires et al. (2004) sugerem a estratégia de interligar os fragmentos com corredores ou manter a proximidade entre eles de até $30 \mathrm{~m}$ para permitir o fluxo de espécies menos plástica e/ou de interior de hábitat, e fragmentos com tamanho e forma que abriguem uma área razoável de hábitat. Quanto maior a distância, mais ocasional ou irregular é o fluxo de indivíduos entre fragmentos. Em distâncias maiores, não há conectividade e as subpopulações ficam isoladas. Para promover a conectividade entre fragmentos, Pereira et al. (2010) citam a construção de pequenos corredores de espécies arbóreas em faixas interligando esses fragmentos.

A maioria dos pontos avaliados apresentaram-se em um cenário crítico de conservação e degradação, alguns deles agravados pela presença de pastagens. A degradação do solo pode ser agravada pela agropecuária, que leva à compactação e à erosão do solo pelo pisoteio do gado (Martins 2007). A faixa de vegetação na nascente não alcançou o raio mínimo de $50 \mathrm{~m}$, como exigido pela legislação. Para conservação das nascentes, Calheiros et al. (2004) recomendam que o pasto e os animais sejam afastados da nascente, pois mesmo que os animais não tenham livre acesso à água, seus dejetos contaminam o terreno e, nos períodos de chuvas, acabam por contaminá-la. Essa contaminação pode provocar o aumento de matéria orgânica na água, o que acarretaria o desenvolvimento exagerado de algas e sua contaminação por organismos patogênicos que infestam os animais e podem atingir o homem.

De acordo com a Política Estadual de Recursos Hídricos da Bahia (Lei n ${ }^{\circ} 11.612 / 2009$ ), a construção de empreendimentos, atividades ou ações que possam alterar a quantidade, a qualidade ou o regime das águas, ou que alterem canais, margens, terrenos marginais, correntes de águas, dentre outras intervenções, como os represamentos encontrados nos Pontos 4 e 5, podem ser realizados apenas com a outorga do órgão ambiental competente. $\mathrm{Na}$ área urbana, o elevado nível das intervenções caracteriza a pior condição dentre os pontos avaliados. O ciclo hidrológico sofre fortes alterações em áreas urbanas devido principalmente à alteração da superfície e à canalização do escoamento, que aumentam a poluição em virtude da contaminação do ar, das superfícies urbanas e do material sólido disposto pela população. O uso de canalização para drenagem é uma prática generalizada no Brasil, e mesmo representando altos custos, geralmente tende a aumentar o problema que pretendia resolver (Tucci 2004).

O único ponto classificado com nível excelente de funcionalidade e características trata-se de uma vegetação em estágio secundário de sucessão e médio de regeneração, de acordo com a Resolução no 5/94 do CONAMA. Ele não pode ser considerado ideal e também está suscetível à degradação por ações antrópicas e animal.

Recomendações. Os trechos diagnosticados de APP do rio Catu necessitam de atenção e medidas de conservação e/ou restauração. As ações recomendadas na chave de tomada de decisões para cada situação estão no Quadro 1.

\section{CONCLUSÕES}

De forma complementar, o Mapeamento, a Avaliação da Integridade Ecológica e o Diagnóstico da Conservação e Degradação possibilitaram a identificação da situação do rio Catu, possibilitando concluir que:

$\checkmark$ A APP ao longo do rio Catu encontra-se em desacordo com a legislação, e as áreas florestadas foram extremamente fragmentadas, dando origem a manchas pequenas e isoladas em uma paisagem predominantemente agropecuária e urbana;

$\checkmark$ Mais da metade dos fragmentos florestais encontramse isolados na paisagem e estão altamente vulneráveis à perda de biodiversidade e a ações antrópicas;

$\checkmark$ Apenas um fragmento (o maior) apresenta menor vulnerabilidade ambiental; entretanto, mesmo considerando a maior distância pré-determinada, sua conectividade estrutural não é viável;

$\checkmark$ O IFF foi eficaz na avaliação ambiental. Este método atendeu às necessidades do estudo, fazendo uma avaliação geral do estado do ecossistema em trechos do rio, dos aspectos relacionados com a sua funcionalidade e estado conservação da vegetação ciliar;

$\checkmark$ A chave de tomada de decisões contemplou as situações encontradas, tornando possível a indicação de ações específicas para cada caso, orientando e servindo de base para as medidas iniciais.

\section{REFERÊNCIAS}

Andrén, H. 1994. Effects of habitat fragmentation on birds and mammals in landscapes with different proportions of suitable habitat: a review. Oikos 71: 355-366. 
Azevedo, A.R.; Silva, V.V. \& Ferreira, A.M.M. 2003. Análise dos fragmentos florestais na Bacia do Rio Turvo, Médio Vale do Rio Paraíba do Sul, RJ. In: Anais de Trabalhos Completos do VI Congresso de Ecologia do Brasil. Editora da Universidade Federal do Ceará, Fortaleza, p. 79-80.

Calheiros, R.O.; Tabai, F.C.V.; Bosquilia, S.V. \& Calamari, M. 2004. Preservação e Recuperação das Nascentes. Comitê das Bacias Hidrográficas dos Rios PCJ - CTRN, Piracicaba.

Delibes, M.; Gaona, P. \& Ferreras, P. 2001. Effects of an attractive sink leading into maladaptive habitat selection. The American Naturalist 158(3): 277-285.

Ferreira, D.A.C. \& Dias, H.C.T. 2004. Situação atual da mata ciliar do ribeirão São Bartolomeu em Viçosa, MG. Revista Árvore 28(4): 617-623.

Forero-Medina, G. \& Vieira, M.V. 2007. Conectividade funcional e a importância da interação organismo-paisagem. Oecologia Brasiliensis 11(4): 493-502.

Ivanauskas, N. \& Barbosa, K.C. 2006. Modelos de RAD para aplicação em diferentes situações em matas ciliares do estado de São Paulo. In: L.M. Barbosa, (coord.), Anais do Workshop sobre Recuperação de Áreas Degradadas em Matas Ciliares, São Paulo, p. 14-23.

Junior, R.F.V. 2008. Diagnóstico de Áreas de Risco de Erosão e Conflito de Uso dos Solos na Bacia do Rio Uberaba. Tese de Doutorado. Faculdade de Ciências Agrárias e Veterinárias, Universidade Estadual Paulista.

Kobiyama, M. 2003. Conceitos de zona ripária e seus aspectos geobiohidrológicos. In: M. Kobiyama, R.V. Silva, T Checchia \& A. Alves (orgs), Anais do I Seminário de Hidrologia Florestal: Zonas Ripárias, Alfredo Wagner, p. 1-13.

Lei $\mathrm{n}^{\mathbf{0}} 11.612$ de 08 de outubro de 2009. Disponível em: $<$ http://www.mp.ba.gov.br/atuacao/ceama/material/legislacoes/h idricos/lei_11612_2009.pdf>; acesso em 19 jul. 2012.

Lei $\mathbf{n}^{\circ}$ 12.651, de 25 de maio de 2012. Disponível em $<$ http://www.planalto.gov.br/ccivil_03/_Ato20112014/2012/Lei/L12651.htm>; acesso em 17 jun. 2012.

Lima, E.A.C.F. \& Carvalho, F. 2004. Proposta de um sistema de áreas de conservação ambiental para o município de Ilha Solteira, SP. In: E. Santos, F. Cavalheiro, J.S.R. Pires, C.H. Oliveira \& A.M.Z.R. Pires (orgs), Faces da Polissemia da Paisagem-Ecologia, Planejamento e Percepção. RiMa, São Carlos, p. 393-406.

Lima, W.P. \& Zakia, M.J.B. 2000. Hidrologia de matas ciliares. In: R.R. Rodrigues \& H.F.L. Leitão Filho (eds), Matas Ciliares: conversação e recuperação. EDUSP, São Paulo, p. 33-44.

Martins, S.V. 2007. Recuperação de Matas Ciliares. 2 ed. Aprenda Fácil Editora, Viçosa.
Odum, E.P. \& Barret, G.W. 2007. Fundamentos de Ecologia. Thompson Learning, São Paulo, p. 374-399.

Pereira, I.M.; Berg, E.V.D. \& Pinto, L.V.A. 2010. Avaliação e proposta de conectividade dos fragmentos remanescentes no campus da Universidade Federal de Lavras, Minas Gerais. Cerne 16(3): 305-321.

Pires, J.S.R.; Pires, A.M.Z.R. \& Santos, J. E. 2004. Avaliação da integridade ecológica em bacias hidrográficas. In: E. Santos, F. Cavalheiro, J.S.R. Pires, C.H. Oliveira \& A.M.Z.R. Pires (orgs), Faces da Polissemia da Paisagem-Ecologia, Planejamento e Percepção. RiMa, São Carlos, p. 123-150.

Ranta, P.; Blom, T.; Niemelã, J.; Joensuu, E. \& Siitonen, M. 1998. The fragmented Atlantic rain forest of Brazil: size, shape and distribution of forest fragments. Biodiversity and Conservation 7: 385-403.

Resolução $\mathrm{n}^{\circ}$ 5, de 04 de maio de 1994. Disponível em $<\mathrm{http}$ //www.mp.ba.gov.br/atuacao/ceama/material/legislacoes/f lora/resol_conama_05_9 4.pdf >; acesso em 19 jul. 2012.

Santos, P.R.P. \& Oliveira, I.B. 2007. Avaliação do gerenciamento das águas subterrâneas da Bacia Hidrográfica do Recôncavo Norte, estado da Bahia, utilizando a concessão da outorga de uso como indicador do nível gestão. In: Anais do XVII Simpósio Brasileiro de Recursos Hídricos, São Paulo.

Saunders, D.A., Hobbs R.J. \& Margules C.R. 1991. Biological consequences of ecosystem fragmentation: a review. Conservation Biology 5: 18-32.

Sgrott, E. 2003. Fitossociologia da zona ripária no estado de Santa Catarina. In: M. Kobiyama, R.V. Silva, T. Checchia \& A. Alves (orgs), Anais do I Seminário de Hidrologia Florestal: Zonas Ripárias, Alfredo Wagner, p. 14-39.

Siligardi, M.; Avolio, F.; Baldaccini, G., Barnabei, S.; Bucci, M.S.; Cappelletti, C.; Chierici, E.; Ciutti, F.; Floris, B.; Franceschini, A.; Mancini, L.; Minciardi, M.R.; Monauni, C.; Negri, P.; Pineschi, G.; Pozzi, S.; Rossi, G.L.; Sansoni, G.; Spaggiari, R.; Tamburro, C. \& Zanetti, M. 2007. IFF 2007 Indice di Funzionalità Fluviale. Nuova versione del metodo revisionata e aggiornata. Agenzia per la Protezione dell'Ambiente e per i Servizi Tecnici (APAT), Roma.

Taylor, P.D.; Fahrig, L.; Henein, K. \& Merriam, G. 1993. Connectivity is a vital element of landscape structure. Oikos 68(3): 571-573.

Tucci, C.E.M. 2004. Gerenciamento integrado das inundações urbanas no Brasil. REGA 1(1): 59-73.

Vannote, R.L.; Minshall, G.W.; Cummins, K.W.; Sedel L, J.R. \& Cushing, C.E. 1980. The River Continuum Concept. Canadian Journal of Fisheries and Aquatic Science. 37: 130-137. 